\title{
Plant-made HIV vaccines and potential candidates
}

Jocelyne Tremouillaux-Guiller ${ }^{1}$, Khaled Moustafa ${ }^{2}$, Kathleen Hefferon ${ }^{3}$, Goabaone Gaobotse ${ }^{4}$, and Abdullah Makhzoum ${ }^{4}$

${ }^{1}$ Faculty of Pharmaceutical Sciences, University François Rabelais, Tours, France.

${ }^{2}$ Arabic Science Archive - ArabiXiv (https://arabixiv.org).

${ }^{3}$ Department of Microbiology, Cornell University, USA.

${ }^{4}$ Department of Biological Sciences \& Biotechnology, Botswana International University of Science \& Technology, Botswana.

Correspondence: klh22@cornell.edu; abmakhzoum@gmail.com

\section{Highlights}

- HIV/AIDS is a partially treatable but not completely curable pandemic disease.

- Major advances have been made to treat patients living with HIV/AIDS.

- Developing HIV vaccines is an ongoing endeavor and moves at an accelerated pace

- Plant molecular pharming is a valuable tool in HIV/AIDS vaccine research.

\begin{abstract}
Millions of people around the world suffer from heavy social and health burdens related to HIV/AIDS and its associated opportunistic infections. To reduce these burdens, preventive and therapeutic vaccines are required. Effective HIV vaccines have been under investigation for several decades using different animal models. Potential plant-made HIV vaccine candidates have also gained attention in the past few years. In addition to this, broadly neutralizing antibodies produced in plants which can target conserved viral epitopes and neutralize mutating HIV strains have been identified. Numerous epitopes of glycoproteins and capsid proteins of HIV-1 are a part of HIV therapy. Here, we discuss some recent findings aiming to produce anti-HIV-1 recombinant proteins in engineered plants for AIDS prophylactics and therapeutic treatments.
\end{abstract}

Keywords: plant made pharmaceuticals; HIV vaccine; AIDS drug; plant molecular pharming/farming; multiepitopic HIV vaccine. 


\section{Introduction}

Acquired Immunodeficiency Syndrome (AIDS) is one of the greatest challenges to global public health today. In 1981, AIDS was identified as a new disease characterized by the dramatic collapse of CD4+T cells and immune responses. This drastic depletion of the immune system can lead to an assortment of opportunistic pathologies in infected subjects. Two years after the discovery of AIDS, a novel retrovirus was identified as the causative agent of AIDS [1] and was formally renamed the Human immunodeficiency virus (HIV) in 1986. HIV belongs to lentiviruses (a subgroup of retrovirus family) and has a genome of two similar single-stranded RNA molecules and several viral proteins packaged within a capsid. Two types of HIV (HIV-1 and HIV-2) have been identified, based on their genetic particularities and various viral antigens. However, HIV-1, and its subtypes, is the major type of HIV responsible for the growing global AIDS pandemic. The HIV-1 genome encodes nine open reading frames. Three of these encode the Group-specific Antigen (Gag), DNA Polymerase (Pol), a reverse transcriptase, and envelope (Env) polyproteins, which are subsequently proteolyzed into individual proteins common to all retroviruses. Its viral envelope comprises trimers of non-covalently linked heterodimers, subunits gp120 and gp41. More than a dozen HIV-1 subtypes and hundreds of circulating HIV-1 recombinant forms (CRFs) have been identified so far [2]. The rapid evolution of HIV envelope (Env) protein (gp120) has serious consequences for immunity to HIV-1 []] .

\section{Demand for HIV vaccines}

By the end of 2018, the World Health Organization (WHO) estimated that 37.9 million people were living with HIV around the world, among them 23.3 million were receiving antiretroviral therapy (ART). Moreover, about 700,000 people contract HIV every year and thousands of others die from subsequent chronic AIDS. Africa remains the most severely affected region, accounting for approximately two thirds of people living with the virus. To complement the efforts of ART, a vaccine is essential to eradicate the HIV/AIDS pandemic and slow down its multifaceted damage. This is desperately needed, particularly in HIV endemic regions where people have little access to ART due to poor socioeconomic status and where molecular pharming can thrive [4] [ㄷ].

At present, there is no HIV vaccine commercially available. Putting in place a prophylactic HIV vaccine is an absolute necessity. The global HIV pandemic continues to grow (due to mortality, number of people living with the HIV-1 virus and newly infected people each 
year), as demonstrated by WHO statistics. On the other hand, current ART medications are costly and require lifelong observance with many side effects.

As early as 1987, the United States carried out the first phase I trial of a candidate vaccine. Nowadays, more than 30 HIV vaccine candidates have been tried in Phase I/II clinical trials, conducted mainly in the US and Europe and involving thousands of healthy volunteers.

\section{Hurdles of HIV prophylactic vaccines}

Despite a lot of human and financial resources that have been allocated to HIV research for decades, the development of an effective HIV vaccine is still elusive. Developing an effective preventive vaccine at low cost is a challenge for health professionals in the $21 \mathrm{st}$ century. The major hurdle behind this failure is the extraordinary genetic diversity of HIV-1 and, more specifically, the high level of variability within the viral envelope (Env) glycoprotein that is the target of neutralizing antibodies [6-8]. Due to high mutation rates (about 1-10 mutations per genome replication cycle), considerable conformational flexibility and extensive glycan coverage, the HIV-1 virus has developed a unique arsenal of mechanisms to evade neutralizing antibodies [9]. After infection, each host contains variants of HIV which are able to escape neutralizing antibodies (nAbs) that are produced. Although envelope structural modifications present a barrier to a broad-based immune response, this problem could be overcome by polyvalent HIV vaccines that recognize conserved domains on the viral envelope [10]. Accumulating evidence and multiple studies suggest that an effective HIV vaccine might be achievable in upcoming years.

\section{Plant-based biofactories}

Plant molecular pharming (PMP) is based on the ability of plants to express different genes for preventive and therapeutic purposes and it holds promise [11]. The production and commercialization of recombinant proteins and pharmaceutical compounds from plants has been optimized and relatively successful over the past few years [11-15]. The concept of PMP as a biofactory was demonstrated earlier on [16] and presents many advantages over conventional systems that rely on bacteria, yeast, insect and animal cell cultures for pharmaceutical products [13]. Engineered plants can properly assemble, fold, glycosylate and produce recombinant proteins at high scale and low cost without the risk of contamination by human pathogens [17]. Seeds harboring pharmaceutical proteins can also be stored at ambient 
temperatures for months or years in certain instances without a loss in activity [18], thus removing substantial requirements of cold chain storage and transportation.

Examples of potential plant-derived vaccines for protection against different infectious diseases [19] and pathologies such as cancer [20], Influenza A virus subtype H1N1(H1N1), Hepatitis B and other pathogens responsible for global human pathologies have been reported $[21,22]$. Several plant secondary metabolites with antimicrobial properties have also been identified as inhibitors of the infection cycle of different pathogens. These metabolites are often part of a plant's defense strategy against biotic and/or abiotic stresses.

\section{HIV vaccine candidates and antibodies expressed in plants}

Several HIV antigens and neutralizing anti-HIV antibodies have been produced in various plant species since 1995 (Table 1) via stable Agrobacterium-mediated transformation or through transient expression systems using plant viral vectors (Figure 1). The ability to elicit multistage broadly neutralizing antibodies (bnAbs) is one of the current strategies used to develop HIV vaccines [23]. A novel anti-HIV-1 bispecific bNAb-lectin fusion protein has recently been expressed in Nicotiana benthamiana using a transient expression system [24]. The HIV-neutralizing human monoclonal antibody 2G12 has also been expressed in tobacco and is now approved for human phase I clinical trials [25]. The 2G12 antibody is one of the broadly neutralizing antibodies that specifically recognizes carbohydrate epitopes on the surface of HIV-1.

The identification of Epitope-focused Antigenic Domains (EADs) also offers a collection of possible targets for the rational design of HIV-1 vaccines [26]. Numerous epitopes of the Env glycoproteins and capsid proteins of HIV-1 are now found in the 'HIV Molecular Immunology Database'. These heterologous HIV-1 Env mixtures expose the immune response to a diversity of Env conformations [27]. An approach to the development of artificial proteins constructed using conservative T-and B-cell epitopes and their mimics is also promising for the development of vaccines against different viruses, including HIV $[\underline{7}, \underline{28}]$. The synthesis of vaccines against HIV-1 using virus-like nanoparticles is another area of research in HIV vaccines [29-32].

An example of a polyvalent vaccine is the $\mathrm{C} 4(\mathrm{~V} 3) 6$ chimeric multi-epitopic protein, modeled upon gp120 and generated to test its immunization capacity against HIV. This protein was expressed in bacteria, then expressed in tobacco and lettuce, and displayed potent antigenic HIV properties with no observed toxicity [33]. The characterization of the C4(V3)6 protein from lettuce showed that this multi-epitopic recombinant protein induced an immune 
response when ingested by mice [34]. Additionally, C4(V3)6 derived from lettuce demonstrated enhanced immunogenic potential compared to E. coli produced epitopes. Further investigations of other multi-epitopic proteins were performed by fusing the multiHIV epitope with glutathione-S-transferase and expressing the fusion protein in recombinant E. coli cells. The multi-HIV epitope construct was expressed in tobacco plants and elicited humoral responses in mice [35]. A multipotent HIV chimeric protein has also been synthesized in the moss plant Physcomitrella patens [36]. This protein was synthesized from gp41 and gp120 epitopes and used to produce the vaccine pol-HIV. Extracts of this recombinant protein were shown to induce specific antibodies in mice, signaling the potential of moss plants as an expression vehicle for the synthesis of HIV antigens and vaccines.

A novel affinity ligand has also been recently described based on the red fluorescent protein DsRed (derived from Discosoma sp.) as a carrier of the epitope ELDKWA that can capture the HIV-neutralizing antibody 2F5 [37]. When the protein fusion DsRed-2F5-Epitope (DFE) was expressed in transgenic tobacco, a yield of $24 \mathrm{mg} \mathrm{kg}-1$ with up to $90 \%$ purity was obtained using heat treatment and immobilized metal-ion affinity chromatography for protein purification. Although DFE is not yet optimized, boosting its expression and increasing its capacity to some folds would make its use in the production and purification of idiotypespecific mAbs cost-effective [37].

In an attempt to assess the immunogenicity of a multivalent HIV vaccine including DNA vector alone or in combination with Env glycoprotein (gp120), it was found that the coadministration of gp120 Env protein components with DNA vaccine leads to early and potent induction of Env V1/V2 IgG binding antibody responses [료]. It was also recently reported that a short DNA vaccine vector (of 172 bp length) derived from the porcine circovirus PCV1 capsid protein promoter, and expressing various HIV-1 subtypes, leads to high immunogenicity of the HIV-1 subtype C candidate DNA vaccines in rodents, at up to 10-fold lower doses than usually used [39].

A multi-epitopic HIV oral immunogenic protein derived from tobacco has been produced and characterized in orally immunized mice without adjuvant co-administration [40]. These multi-epitopic HIV constructs derived from tobacco chloroplasts were able to induce T-helper (i.e. $\mathrm{CD} 4^{+}$and $\mathrm{CD} 8^{+}$cells) specific responses such as IFN- $\gamma$-production after stimulation with HIV peptides. Together, these findings illustrate well the immunogenic potential of plant-made HIV multi-epitopic proteins in an oral immunization proof-of-concept [40]. 
Recently, evolutionarily conserved epitopes between Feline immunodeficiency virus (FIV) and HIV were explored as a means of developing an effective vaccine [41]. In this study, Sahay and colleagues identified overlapping peptides that elicited $\mathrm{T}$ cell immunity in HIV-infected people and FIV-vaccinated cats. Four of the conserved epitopes were then used to produce four multiple antigen peptides (MAPs) which were tested against FIV in cats. Increases in $\mathrm{CD}^{+}$and $\mathrm{CD}^{+} \mathrm{T}$ cell MAP responses were observed in nearly $80 \%$ of the cats, implying protection against FIV [41]. This criterion can be similarly applied in humans to select for protective HIV-1 peptides that can be used to formulate an effective vaccine against HIV-1. An in silico approach has recently been developed to predict anti-HIV activities and save time and money in screening for potential HIV/AIDS drugs [42].

Three proteins that can neutralize HIV were recently produced in rice endosperm [43]. These included the monoclonal antibody $2 \mathrm{G} 12$ as well as cyanovirin-N and griffithsin (GFRT). It was found that a cocktail of these components was able to neutralize HIV by binding to gp120. It was further discovered that the use of this cocktail in conjunction with rice endosperm crude extracts strengthened binding to gp120. When synthesized in transgenic plants, the extracts of these proteins also improved binding to gp120 while at the same time neutralizing the virus in a more potent manner than a conventionally produced cocktail [43]. Griffithsin (GFRT), an anti-HIV carbohydrate-binding protein (lectin) derived from algae and considered to be one of the most efficient viral entry inhibitors, has been synthesized in tobacco and lettuce plants at relatively high yield levels particularly when the open reading frame was fused to the Zera signal peptide [44]. Tobacco and lettuce may therefore be ideal host expression systems for the synthesis of GRFT as an HIV inhibitor.

A plant virus vector system based on Tobacco mosaic virus has also been used to produce GRFT in $N$. benthamiana GRFT accumulated to more than $1 \mathrm{~g} / \mathrm{kg}$ fresh weight in fresh leaf material and exhibited gp120 binding potential and efficacy that was similar to that produced in E. coli and native GRFT respectively. Fuqua et al. (2015) were able to develop an inexpensive and industrial scale purification system for GRFT that could be viable in resource-poor settings [45]. The authors' technique could provide multi-kilogram quantities of GRFT at low cost. A further study demonstrated the feasibility of plant-produced GRFT using a Tobacco mosaic virus vector inoculated into $N$. benthamiana plants via a highpressure spray [46]. According to the model set up by these authors, $20 \mathrm{~kg}$ of GRFT can be generated every year, with a yield of 0.37 grams of GRFT per $\mathrm{kg}$ of plant biomass and a projected cost estimated at \$USD 0.32 per dose ( 3 milligrams). This is in comparison to the current cost of the pre-exposure prophylaxis drugs emtricitabine and tenofovir disoproxil 
fumarate (which ranges from $\$ 1,300$ to over $\$ 1,700$ per month). Using transient plant-based platforms for the production of antibodies can reduce cost and capital investment by about $50 \%$ compared to traditional biomanufacturing platforms that use mammalian cells [47].

Tobacco has also been used to synthesize the lectin, cyanovirin-N (CVN) [48]. Another plant lectin (BanLec) seems to effectively neutralize HIV-1 by targeting a subset of dense mannose glycans of the glycosylated HIV-1 envelope protein, gp120, via bidentate interactions spanning two carbohydrate binding sites present on each BanLec monomer [49]. BanLec (banana lectin) was initially isolated from bananas with anti-HIV replication activity [50].

B cell epitopes for the production of broadly neutralizing antibodies (bNAbs) against HIV also exist. bNAbs can induce either passive or innate cellular responses to HIV-1 [51]. HIV Env gp140 antigens have recently been produced in a transient expression system in Nicotiana benthamiana by using two virus isolates (CAP256 SU and Du151) [52]. The HIV antigen, P24, has been synthesized in the green alga Chlamydomonas, with the recombinant protein constituting $0.25 \%$ of the total cellular protein [53]. Constructs of P24 and Gag, a HIV-1 coat protein gene, have been inoculated into $N$. glutinosa and $N$. benthamiana plants where it was discovered that P24 replicated in the inoculated plants while Gag did not [54]. This demonstrated the presence of P24, and therefore the potential of high-throughput p24 production in plants. It has been previously shown that a transient expression system using the gene silencing suppressor protein P19 helped increase the expression of HIV-1 Nef in $N$. benthamiana plants [55].

\section{Conclusion and Perspective}

There is an urgent need to uproot the HIV/AIDS epidemic everywhere in the world in whatever way possible by targeting its conserved and/or variable structures. The facility and cost effectiveness of plant expression systems can help expedite preventive and therapeutic HIV vaccine development. Once an effective HIV vaccine is developed sooner or later in whatever biological approach, plant molecular pharming may turn out to be a solution of choice for producing such vaccine thanks to its numerous advantages over other bio-drug production platforms. Economical and highly efficacious plant-made biopharmaceuticals, including vaccines, broadly neutralizing monoclonal antibodies and antiretroviral microbicides could have a significant impact on HIV epidemiology, incidence and prevalence. Ultimately, plants that harbor therapeutic molecules can grow almost everywhere without the need for sophisticated or expensive infrastructures to produce potential HIV vaccine candidates so that poor people can have access to these vaccines easily. Kessans $e t$ 
al. (2016) demonstrated the potential of combining a plant vaccine into a heterologous prime/boost vaccination regimen, in which plant made vaccines, would provide suitable booster vaccines due to the large amount of vaccine material required for repeated booster shots [56]. Others have also demonstrated in animal studies the value that PMP could have for effective vaccine prime/boost strategies $[\underline{57}, \underline{58}]$.

The next steps will be to continue the push toward the development of facilities which enable plant-made vaccines and antiretrovirals to be produced in resource-poor settings [59]. HIV vaccines and antiretroviral proteins that could meet the world's demands could never be produced under the current prohibitively expensive restrictions of mammalian cell production and purification systems. Plant-based platforms, on the other hand, stand a reasonable chance of meeting this goal $[\underline{60}, \underline{61}]$.

\section{Conflict of interest: none.}

\section{References}

1. Barré-Sinoussi F, Chermann J-C, Rey F, Nugeyre MT, Chamaret S, Gruest J, Dauguet C, Axler-Blin C, Vézinet-Brun $F$, Rouzioux $C$ : Isolation of a T-lymphotropic retrovirus from a patient at risk for acquired immune deficiency syndrome (AIDS). Science 1983, 220:868-871.

2. Stephenson KE, Neubauer GH, Reimer U, Pawlowski N, Knaute T, Zerweck J, Korber BT, Barouch DH: Quantification of the epitope diversity of HIV-1-specific binding antibodies by peptide microarrays for global HIV-1 vaccine development. Journal of immunological methods 2015, 416:105-123.

3. Haddox HK, Dingens AS, Hilton SK, Overbaugh J, Bloom JD: Mapping mutational effects along the evolutionary landscape of HIV envelope. Elife 2018, 7.

4. Murad S, Fuller S, Menary J, Moore C, Pinneh E, Szeto T, Hitzeroth I, Freire M, Taychakhoonavudh $\mathrm{S}$, Phoolcharoen $\mathrm{W}$, et al.: Molecular Pharming for low and middle income countries. Curr Opin Biotechnol 2019, 61:53-59.

5. Tsekoa TL, Singh AA, Buthelezi SG: Molecular farming for therapies and vaccines in Africa. Curr Opin Biotechnol 2019, 61:89-95.

6. Asbach B, Meier JP, Pfeifer M, Kostler J, Wagner R: Computational Design of Epitope-Enriched HIV-1 Gag Antigens with Preserved Structure and Function for Induction of Broad CD8(+) T Cell Responses. Sci Rep 2018, 8:11264.

7. Rudometov AP, Chikaev AN, Rudometova NB, Antonets DV, Lomzov AA, Kaplina ON, Ilyichev AA, Karpenko LI: Artificial Anti-HIV-1 Immunogen Comprising Epitopes of Broadly Neutralizing Antibodies 2F5, 10E8, and a Peptide Mimic of VRC01 Discontinuous Epitope. Vaccines (Basel) 2019, 7.

8. van Schooten J, van Gils MJ: HIV-1 immunogens and strategies to drive antibody responses towards neutralization breadth. Retrovirology 2018, 15:74.

9. Rathore U, Purwar M, Vignesh VS, Das R, Kumar AA, Bhattacharyya S, Arendt H, DeStefano J, Wilson A, Parks C, et al.: Bacterially expressed HIV-1 gp120 outer-domain fragment immunogens with improved stability and affinity for CD4-binding site neutralizing antibodies. J Biol Chem 2018, 293:15002-15020. 
10. Marusic C, Vitale A, Pedrazzini E, Donini M, Frigerio L, Bock R, Dix PJ, McCabe MS, Bellucci M, Benvenuto E: Plant-based strategies aimed at expressing HIV antigens and neutralizing antibodies at high levels. Nef as a case study. Transgenic research 2009, 18:499.

11. Rybicki EP: Plant-made vaccines and reagents for the one health initiative. Human vaccines \& immunotherapeutics 2017, 13:2912-2917.

12. Jensen PE, Scharff LB: Engineering of plastids to optimize the production of high-value metabolites and proteins. Curr Opin Biotechnol 2019, 59:8-15.

13. Moustafa K, Makhzoum A, Tremouillaux-Guiller J: Molecular farming on rescue of pharma industry for next generations. Crit Rev Biotechnol 2016, 36:840-850.

14. Nogueira M, Enfissi EM, Almeida J, Fraser PD: Creating plant molecular factories for industrial and nutritional isoprenoid production. Curr Opin Biotechnol 2018, 49:80-87.

15. Schiermeyer A: Optimizing product quality in molecular farming. Curr Opin Biotechnol 2019, 61:15-20.

16. Barta A, Sommergruber K, Thompson D, Hartmuth K, Matzke MA, Matzke AJ: The expression of a nopaline synthase-human growth hormone chimaeric gene in transformed tobacco and sunflower callus tissue. Plant molecular biology 1986, 6:347-357.

17. Lomonossoff GP, D'Aoust M-A: Plant-produced biopharmaceuticals: a case of technical developments driving clinical deployment. Science 2016, 353:1237-1240.

18. Boothe J, Nykiforuk C, Shen Y, Zaplachinski S, Szarka S, Kuhlman P, Murray E, Morck D, Moloney MM: Seed-based expression systems for plant molecular farming. Plant Biotechnology Journal 2010, 8:588-606.

19. Sainsbury F: Innovation in plant-based transient protein expression for infectious disease prevention and preparedness. Curr Opin Biotechnol 2019, 61:110-115.

20. Dent M, Matoba N: Cancer biologics made in plants. Current Opinion in Biotechnology 2020, 61:82-88.

21. Chan HT, Daniell H: Plant-made oral vaccines against human infectious diseases-are we there yet? Plant biotechnology journal 2015, 13:1056-1070.

22. Rybicki EP: Plant-based vaccines against viruses. Virol J 2014, 11:205.

23. Andrabi R, Bhiman JN, Burton DR: Strategies for a multi-stage neutralizing antibody-based HIV vaccine. Curr Opin Immunol 2018, 53:143-151.

24. Seber Kasinger LE, Dent MW, Mahajan G, Hamorsky KT, Matoba N: A novel anti-HIV-1 bispecific bNAb-lectin fusion protein engineered in a plant-based transient expression system. Plant biotechnology journal 2019, 17:1646-1656.

25. Ma JK, Drossard J, Lewis D, Altmann F, Boyle J, Christou P, Cole T, Dale P, van Dolleweerd CJ, Isitt $V$, et al.: Regulatory approval and a first-in-human phase I clinical trial of a monoclonal antibody produced in transgenic tobacco plants. Plant Biotechnol J 2015, 13:1106-1120.

26. Wang H, Chen X, Wang D, Yao C, Wang Q, Xie J, Shi X, Xiang Y, Liu W, Zhang L: Epitope-focused immunogens against the CD4-binding site of HIV-1 envelope protein induce neutralizing antibodies against auto- and heterologous viruses. J Biol Chem 2018, 293:830-846.

27. Pankrac J, Klein K, McKay PF, King DF, Bain K, Knapp J, Biru T, Wijewardhana CN, Pawa R, Canaday DH: A heterogeneous human immunodeficiency virus-like particle (VLP) formulation produced by a novel vector system. NPJ vaccines 2018, 3:2.

28. Korber B, Fischer W: T cell-based strategies for HIV-1 vaccines. Hum Vaccin Immunother 2019:110.

29. Cervera L, Godia F, Tarres-Freixas F, Aguilar-Gurrieri C, Carrillo J, Blanco J, Gutierrez-Granados S: Production of HIV-1-based virus-like particles for vaccination: achievements and limits. Appl Microbiol Biotechnol 2019, 103:7367-7384.

30. Hefferon K: Plant Virus Expression Vectors: A Powerhouse for Global Health. Biomedicines 2017, 5.

31. Hefferon KL: Repurposing Plant Virus Nanoparticles. Vaccines (Basel) 2018, 6. 
32. Rybicki EP: Plant molecular farming of virus-like nanoparticles as vaccines and reagents. Wiley Interdisciplinary Reviews: Nanomedicine and Nanobiotechnology 2019:e1587.

33. Loh H-S, Green BJ, Yusibov V: Using transgenic plants and modified plant viruses for the development of treatments for human diseases. Current opinion in virology 2017, 26:81-89.

34. Govea-Alonso DO, Gómez-Cardona EE, Rubio-Infante N, García-Hernández AL, Varona-Santos JT, Salgado-Bustamante M, Korban SS, Moreno-Fierros L, Rosales-Mendoza S: Production of an antigenic C4 (V3) 6 multiepitopic HIV protein in bacterial and plant systems. Plant Cell, Tissue and Organ Culture (PCTOC) 2013, 113:73-79.

The successfully synthesized CA(V3)6 multi-epitopic HIV protein in E. Coli was able to induce antibodies against 5 different $\mathrm{V} 3$ sequences from different isolates. The gene encoding this protein, when introduced into an E. Coli expression strain, leads to the overexpression of the $\mathrm{C} 4(\mathrm{~V} 3) 6$ protein through the induction of isopropylb-D-1-thiogalactopyranoside (IPTG). The authors report that the introduction of the protein in tobacco plant through a vector led to the rescue of a few $\mathrm{Kan}^{\mathrm{R}}$ lines. When cultured into full-grown plants, these plants expressed normal phenotype yet they were confirmed to carry the transgene. Additionally, the authors report that plants grown from seeds of these plants were also found to be transformed with the $\mathrm{C} 4(\mathrm{~V} 3) 6$ construct.

35. Rosales-Mendoza S, Rubio-Infante N, Monreal-Escalante E, Govea-Alonso DO, García-Hernández AL, Salazar-González JA, González-Ortega O, Paz-Maldonado LT, Moreno-Fierros L: Chloroplast expression of an HIV envelop-derived multiepitope protein: towards a multivalent plant-based vaccine. Plant Cell, Tissue and Organ Culture (PCTOC) 2014, 116:111-123.

36. Orellana-Escobedo L, Rosales-Mendoza S, Romero-Maldonado A, Parsons J, Decker EL, MonrealEscalante E, Moreno-Fierros L, Reski R: An Env-derived multi-epitope HIV chimeric protein produced in the moss Physcomitrella patens is immunogenic in mice. Plant Cell Rep 2015, 34:425-433.

A multi-epitope HIV protein comprising a set of env epitopes (C4, V3 loop, and four variants of ELDKWA) has been expressed in the transgenic lines of moss Physcomitrella patens as an expression host. The immunogenic potential of 'Poly HIV' was revealed by immunization assays in the BALB / c mice

37. Ruhl C, Knodler M, Opdensteinen P, Buyel JF: A linear epitope coupled to DsRed provides an affinity ligand for the capture of monoclonal antibodies. J Chromatogr $A$ 2018, 1571:55-64.

38. Pantaleo G, Janes $H$, Karuna S, Grant S, Ouedraogo GL, Allen M, Tomaras GD, Frahm N, Montefiori DC, Ferrari G: Safety and immunogenicity of a multivalent HIV vaccine comprising envelope protein with either DNA or NYVAC vectors (HVTN 096): a phase 1b, double-blind, placebo-controlled trial. The Lancet HIV 2019, 6:e737-e749.

39. Chapman R, Rybicki EP: Use of a Novel Enhanced DNA Vaccine Vector for Preclinical Virus Vaccine Investigation. Vaccines 2019, 7:50.

40. Rubio-Infante N, Govea-Alonso DO, Romero-Maldonado A, Garcia-Hernandez AL, IlhuicatziAlvarado D, Salazar-Gonzalez JA, Korban SS, Rosales-Mendoza S, Moreno-Fierros L: A PlantDerived Multi-HIV Antigen Induces Broad Immune Responses in Orally Immunized Mice. Mol Biotechnol 2015, 57:662-674.

In this study, Rubio-Infante and his Collaborators demonstrated that the Multi-HIV protein derived from tobacco chloroplasts was capable of inducing both humoral and cellular responses of the immune system. This plant-derived chimeric protein can serve as a broad immunogen, and its production in edible crops has a potential for use in HIV vaccine development, rendering it as a low-cost production vaccine system. 
41. Sahay B, Aranyos AM, Mishra M, McAvoy AC, Martin MM, Pu R, Shiomitsu S, Shiomitsu K, Dark MJ, Sanou MP: Immunogenicity and Efficacy of a Novel Multi-Antigenic Peptide Vaccine Based on Cross-Reactivity between Feline and Human Immunodeficiency Viruses. Viruses 2019, 11:136.

42. Stolbov L, Druzhilovskiy D, Rudik A, Filimonov D, Poroikov V, Nicklaus M: AntiHIV-Pred: Webresource for in silico prediction of anti-HIV/AIDS activity. Bioinformatics 2019.

43. Vamvaka E, Farre G, Molinos-Albert LM, Evans A, Canela-Xandri A, Twyman RM, Carrillo J, Ordonez RA, Shattock RJ, O'Keefe BR, et al.: Unexpected synergistic HIV neutralization by a triple microbicide produced in rice endosperm. Proc Natl Acad Sci U S A 2018, 115:E7854E7862.

44. Vafaee $\mathrm{Y}$, Alizadeh $\mathrm{H}$ : Heterologous production of recombinant anti-HIV microbicide griffithsin in transgenic lettuce and tobacco lines. Plant Cell, Tissue and Organ Culture (PCTOC) 2018, 135:85-97.

45. Fuqua JL, Wanga V, Palmer KE: Improving the large scale purification of the HIV microbicide, griffithsin. BMC Biotechnol 2015, 15:12.

46. Alam A, Jiang L, Kittleson GA, Steadman III KD, Nandi S, Fuqua JL, Palmer KE, Tusé D, McDonald KA: Technoeconomic Modeling of Plant-Based Griffithsin Manufacturing. Frontiers in bioengineering and biotechnology 2018, 6:102.

47. Nandi S, Kwong AT, Holtz BR, Erwin RL, Marcel S, McDonald KA: Techno-economic analysis of a transient plant-based platform for monoclonal antibody production. MAbs 2016, 8:14561466.

48. Opdensteinen P, Clodt JI, Müschen CR, Filiz VM, Buyel JF: A combined ultrafiltration/diafiltration step facilitates the purification of cyanovirin- $\mathrm{N}$ from transgenic tobacco extracts. Frontiers in bioengineering and biotechnology 2018, 6:206.

49. Hopper JT, Ambrose S, Grant OC, Krumm SA, Allison TM, Degiacomi MT, Tully MD, Pritchard LK, Ozorowski G, Ward AB: The tetrameric plant lectin BanLec neutralizes HIV through bidentate binding to specific viral glycans. Structure 2017, 25:773-782. e775.

50. Swanson MD, Winter HC, Goldstein IJ, Markovitz DM: A lectin isolated from bananas is a potent inhibitor of HIV replication. Journal of Biological Chemistry 2010, 285:8646-8655.

51. Wijesundara DK, Ranasinghe C, Grubor-Bauk B, Gowans EJ: Emerging Targets for Developing T Cell-Mediated Vaccines for Human Immunodeficiency Virus (HIV)-1. Front Microbiol 2017, 8:2091.

52. Margolin E, Chapman R, Meyers A, van Diepen M, Ximba P, Hermanus T, Crowther C, Weber B, Morris L, Williamson A-L: Production and immunogenicity of soluble plant-produced HIV-1 subtype C envelope gp140 immunogens. Frontiers in Plant Science 2019, 10:1378.

The authors showed that when recombinant $A$. tumefaciens strains encoding the soluble HIV-1 gp140 antigens made from CAP256 SU and Du151 Env genes were introduced into $N$. benthamiana plants, both proteins resulted in severe pathology in the plants. It was discovered that the pathology caused by Du151 gp140 was more severe, with necrosis observed after only 5 days. More plants were infiltrated with these antigens leading to the mean recovery of $4.9 \mathrm{mg} / \mathrm{kg}$ and $6.2 \mathrm{mg} / \mathrm{kg}$ for Du151 and CAP256 SU respectively.

53. Barahimipour R, Neupert J, Bock R: Efficient expression of nuclear transgenes in the green alga Chlamydomonas: synthesis of an HIV antigen and development of a new selectable marker. Plant molecular biology 2016, 90:403-418. 
54. Kachoie EA, Behjatnia SAA, Kharazmi S: Expression of Human Immunodeficiency Virus type 1 (HIV-1) coat protein genes in plants using cotton leaf curl Multan betasatellite-based vector. PloS one 2018, 13:e0190403.

55. Lombardi R, Circelli P, Villani ME, Buriani G, Nardi L, Coppola V, Bianco L, Benvenuto E, Donini M, Marusic C: High-level HIV-1 Nef transient expression in Nicotiana benthamiana using the P19 gene silencing suppressor protein of Artichoke Mottled Crinckle Virus. BMC biotechnology 2009, 9:96.

56. Kessans SA, Linhart MD, Meador LR, Kilbourne J, Hogue BG, Fromme P, Matoba N, Mor TS: Immunological Characterization of Plant-Based HIV-1 Gag/Dgp41 Virus-Like Particles. PLOS One 2016, 11:e0151842.

57. Daniell H, Rai V, Xiao Y: Cold chain and virus-free oral polio booster vaccine made in lettuce chloroplasts confers protection against all three poliovirus serotypes. Plant biotechnology journal 2019.

58. Regnard GL, de Moor WRJ, Hitzeroth, II, Williamson AL, Rybicki EP: Xenogenic rolling-circle replication of a synthetic beak and feather disease virus genomic clone in 293TT mammalian cells and Nicotiana benthamiana. J Gen Virol 2017, 98:2329-2338.

59. Habibi P, Daniell H, Soccol CR, Grossi-de-Sa MF: The potential of plant systems to break the HIVTB link. Plant Biotechnol J 2019, 17:1868-1891.

60. Buyel JF, Twyman RM, Fischer R: Very-large-scale production of antibodies in plants: The biologization of manufacturing. Biotechnol Adv 2017, 35:458-465.

61. Holtz BR, Berquist BR, Bennett LD, Kommineni VJ, Munigunti RK, White EL, Wilkerson DC, Wong KY, Ly LH, Marcel S: Commercial-scale biotherapeutics manufacturing facility for plantmade pharmaceuticals. Plant Biotechnol J 2015, 13:1180-1190.

62. Rubio-Infante N, Govea-Alonso DO, Alpuche-Solís ÁG, García-Hernández AL, Soria-Guerra RE, Paz-Maldonado LT, Ilhuicatzi-Alvarado D, Varona-Santos JT, Verdín-Terán L, Korban SS: A chloroplast-derived C4V3 polypeptide from the human immunodeficiency virus (HIV) is orally immunogenic in mice. Plant molecular biology 2012, 78:337-349.

63. Matoba N, Kajiura H, Cherni I, Doran JD, Bomsel M, Fujiyama K, Mor TS: Biochemical and immunological characterization of the plant-derived candidate human immunodeficiency virus type 1 mucosal vaccine CTB-MPR. Plant Biotechnol J 2009, 7:129-145.

64. Matoba N, Magerus A, Geyer BC, Zhang Y, Muralidharan M, Alfsen A, Arntzen CJ, Bomsel M, Mor TS: A mucosally targeted subunit vaccine candidate eliciting HIV-1 transcytosis-blocking Abs. Proc Natl Acad Sci U S A 2004, 101:13584-13589.

65. Meyers A, Chakauya E, Shephard E, Tanzer FL, Maclean J, Lynch A, Williamson A-L, Rybicki EP: Expression of HIV-1 antigens in plants as potential subunit vaccines. $B M C$ biotechnology 2008, 8:53.

66. Gonzalez-Rabade N, McGowan EG, Zhou F, McCabe MS, Bock R, Dix PJ, Gray JC, Ma JK: Immunogenicity of chloroplast-derived HIV-1 p24 and a p24-Nef fusion protein following subcutaneous and oral administration in mice. Plant Biotechnol J 2011, 9:629-638.

67. Lindh I, Bråve A, Hallengärd D, Hadad R, Kalbina I, Strid Å, Andersson S: Oral delivery of plantderived HIV-1 p24 antigen in low doses shows a superior priming effect in mice compared to high doses. Vaccine 2014, 32:2288-2293.

68. Perez-Filgueira DM, Brayfield BP, Phiri S, Borca MV, Wood C, Morris TJ: Preserved antigenicity of HIV-1 p24 produced and purified in high yields from plants inoculated with a tobacco mosaic virus (TMV)-derived vector. J Virol Methods 2004, 121:201-208.

69. Lindh I, Kalbina I, Thulin S, Scherbak N, Savenstrand H, Brave A, Hinkula J, Strid A, Andersson S: Feeding of mice with Arabidopsis thaliana expressing the HIV-1 subtype C p24 antigen gives rise to systemic immune responses. APMIS 2008, 116:985-994. 
Table 1. Examples of plant-derived vaccine candidates produced in plants and tested in animals against HIV.

\begin{tabular}{|c|c|c|c|c|}
\hline $\begin{array}{l}\text { HIV } \\
\text { Antigen }\end{array}$ & $\begin{array}{l}\text { Produced } \\
\text { in (plant) }\end{array}$ & $\begin{array}{l}\text { Tested in } \\
\text { (animal) }\end{array}$ & Observed Immunogenicity & Reference \\
\hline $\mathrm{C} 4(\mathrm{~V} 3) 6$ & Lettuce & Mice & $\begin{array}{l}\text { Induction of humoral immune response. } \\
\text { Induction of cell-mediated immune response. }\end{array}$ & [34] \\
\hline C4V3 & Tobacco & Mice & $\begin{array}{l}\text { Induction of systemic mucosal antibody } \\
\text { response; induction of mucosal antibody } \\
\text { response; induction of T cell proliferation. }\end{array}$ & [62] \\
\hline CTB-MPR & Tobacco & Mice & $\begin{array}{l}\text { Induction of serum antibodies; induction of } \\
\text { mucosal antibodies. }\end{array}$ & [63] \\
\hline CTB-P1 & Tobacco & Mice & $\begin{array}{l}\text { Serum IgG response; mucosal IGA response; } \\
\text { induction of immunological memory. }\end{array}$ & [64] \\
\hline Gp41 & Tobacco & Mice & $\begin{array}{l}\text { Serum antibody responses; } \\
\text { CD4 and CD8 T cell responses. }\end{array}$ & {$[\underline{56}]$} \\
\hline Multi-HIV & Tobacco & Mice & $\begin{array}{l}\text { Induction of antibody and cellular responses. } \\
\text { Induction of T cell immune response. }\end{array}$ & [40] \\
\hline Multi-HIV & Tobacco & Mice & Induction of humoral response. & [35] \\
\hline $\mathrm{p} 17 / \mathrm{p} 24$ & Tobacco & Mice & $\begin{array}{l}\text { Induction of humoral immune response. } \\
\text { Induction of T cell immune response. }\end{array}$ & [65] \\
\hline p24 & Tobacco & Mice & Serum IgG response. & [66] \\
\hline p24 & Arabidopsis & Mice & Serum IgG response. & [67] \\
\hline p24 & Tobacco & Rabbit & $\begin{array}{l}\text { Induction of specific humoral immune } \\
\text { response. }\end{array}$ & [68] \\
\hline P24 & Arabidopsis & Mice & Serum IgG response. & [69] \\
\hline Poly-HIV & $\begin{array}{l}\text { Physcomitrell } \\
\text { a patens }\end{array}$ & Mice & Induction of specific antibody response. & [36] \\
\hline
\end{tabular}


Figure1A. Stable Agrobacterium tumefaciens-mediated transformation. HIV-1 gene (up-left) is introduced into plant tissues within an optimized expression cassette of Ti-plasmid (Ti: for tumor inducing) of A. tumefaciens. Wounded leaf explants are transformed by insertion of T-DNA (a transferable T-DNA segment from the Ti-plasmid) into plant genome (1-2). Transgenic cells harboring HIV transgene can grow on kanamycin-resistant medium (3). Organogenesis generates plantlets, then plants cultivated in greenhouse setting 6 months later (4-5). The insertion of HIV-1 gene in plant tissues is verified by PCR/RT-PCR analysis prior to purification of the corresponding recombinant protein (6-7).

Figure 1-B. Transient expression process in plants mediated by Agrobacterium tumefaciens. HIV-1 gene (up-left) is introduced into plant tissues within an optimized expression cassette of Ti-plasmid (Ti: for tumor inducing) of $A$. tumefaciens (1). Agrobacterium mixture is introduced into $N$. benthamiana leaf tissues by agroinfiltration. Either (a) by weak vacuum agroinfiltration from leaf shoots (0.8-0.9 bar for 20-30 seconds) or (b) by needleless syringe agroinfiltration at the level of the epidermis on the back side) (2). Leaf explants are transformed by insertion of Ti- T-DNA (a transferable T-DNA segment from the Ti-plasmid) into plant genome (3). After infiltration with the $A$. tumefaciens mixture, the leaf tissues are incubated for 4-6 days (full expression of a HIV-1 gene in agroinfiltred leaves takes place 3-4 days later (4). Then, downstream processes are performed: leaf homogenization, purification by dialysis (remove salts), HIV-1 protein concentration (5). The insertion of HIV-1 gene in plant tissues is verified by PCR/RT-PCR analysis, prior to purification of the recombinant proteins. 6).* Transient expression is a fast and efficient process for producing wide amounts of recombinant proteins, compared to the stable transformation process via Agrobacterium tumefaciens. Plant species, development stage and physiological status of plant play a crucial in the efficiency of the agroinfiltration process for producing recombinant proteins.

Abbreviations: HIV: Human immunodeficiency virus. $\left({ }^{*}\right)$ In disarmed Ti-T-DNA (Binary vector): an expression cassette used for the insertion and expression of the HIV-1 gene in plants. LB: left border; Tnos: terminator of the gene coding for nopaline synthase; HIV-1 gene coding for an antigen chimeric protein; p35s: 35s promoter of CaMV (cauliflower mosaic virus); nptll: gene encoding neomycin phosphotransferase, conferring resistance to kanamycin; pnos: promoter of the gene coding for nopaline synthase; RB: right border. 